\title{
A lighting coordinate database for 3D art objects
}

\author{
Erhan Dikel*, Cengiz Yener \\ Department of Interior Architecture and Environmental Design, Faculty of Art, Design and Architecture, Bilkent University, 06800 Ankara, Turkey
}

Received 15 July 2005; received in revised form 27 September 2005; accepted 20 January 2006

\begin{abstract}
Artists making three-dimensional art objects have an idea in their minds about how to illuminate their creations. For museums and galleries to illuminate these objects successfully according to the ideas of the artist, the types of light sources and their locations must be known. To fulfil this requirement, we propose a lighting coordinate database (LCD) to establish the coordinates of light sources. We describe two possible methods of obtaining data for this database: a computer software method and a hardware method. The head of Michelangelo's David is used to test the applicability of the two methods. In the software method, the scanned image of David's head is illuminated on the computer screen and data for the location of light sources are created. In the hardware method, a second set of data is created by illuminating a scale model of David using light emitting diodes (LED).
\end{abstract}

(C) 2006 Elsevier Ltd. All rights reserved.

Keywords: Lighting; Museum; Art gallery; Exhibition lighting; Led technology; Lighting coordinates database

\section{Introduction}

The Illuminating Engineering Society of North America (IESNA) [1] defines the highest responsibility of a museum as "to study and take care of its collections and to manage their effective public display." From the lighting point of view, effective public display in a museum requires that two things be considered at the same time: the art object itself and the need to illuminate it by using artificial light sources. The successful approach should be to illuminate the object so that it most closely resembles what the artist had in mind.

At present, curators or lighting designers illuminate art objects according to their own technical backgrounds, design skills and creativity using available lighting techniques and technologies for specific exhibitions. Naturally, because of this approach, technical staff in different museums could illuminate the same object in different ways, resulting in different effects. Artists, despite the fact that they created the objects, usually have no control over lighting design and the resulting effect of their own creations. However, "transmitting the artist's values on

\footnotetext{
${ }^{*}$ Corresponding author. Tel.: + 903122902578 ; fax: + 903122664136.

E-mail address: dikel@bilkent.edu.tr (E. Dikel).
}

objects, to spectators through lighting techniques without changing the meaning," is defined as the task of the profession of lighting designers [2].

This study proposes a lighting coordinates database (LCD), which enables artists to have control over the appearance of their creations. Such a database guides curators and lighting designers by giving them the number, the quality, and most importantly, the coordinates of the locations of light sources. LCD can be developed by using either suitable computer software or a three-dimensional (3D) model such as the proposed spherical lighting positioning system (SLPS). A database of lighting coordinates can help to standardize the appearance of an art object in every exhibition, so that in future exhibitions, the desired illumination effect in the artist's mind will be achieved.

\section{Lighting quality in museums}

The quality of light is a major requirement for good visual perception, especially in a place where the visual medium is an art object. Veitch [3] defines lighting quality as a term "used to describe all of the factors in a lighting installation [...] which exists when the luminous conditions support the behavioural needs of individuals in the lit 
space." The relationship between the needs of visitors and the museum objects are noted in her definition. The quality of light is the fundamental issue of contemporary lighting. It has a strong effect on how the illuminated object is perceived in its formative, dimensional, textural, surface and colour properties. As IESNA emphasizes, "good lighting quality can support visual performance, improve interpersonal communication and our feelings of wellbeing. However, poor lighting quality can be uncomfortable and can inhibit visual performance" [4].

Quality of light is essential, but it is not the only factor which improves the visual experience of visitors. The direction of light sources and spectral distribution properties should be considered in every lighting application. In museum lighting, the shapes, forms and colours of art objects can be emphasized or concealed by using light. The direction of illumination is especially important when viewing 3D objects: "light from multiple directions models a sculpture, expressing depth by highlighting some areas while allowing others to fall into shadow" [5]. Shadow is the most fundamental necessity for creating the right visual conditions for 3D objects. According to the IESNA Lighting Handbook [6], "a degree of shadow is a significant visual clue to the solidity of an art object." The balance between light and shadow is important in the right perception of forms, that different linear directions of light, cause shadows of varying shape and density [7].

As well as shadow, colour rendition of light sources must be considered in every application. When an object is illuminated under a light source from a certain direction, the colour rendition property of the light sources should match the desired colour appearance of the object. In the conditions where good colour rendering and detail acuity is necessary, the spectral distribution of the light source must be selected carefully [8].

\section{Background and related work}

Positioning light sources in a global setting, and simulating a desired or a real lighting situation, dates back to the 1930s. The early examples, related mostly to building sciences, are the "Solatron" in Cornell's College of Architecture, the "Heliodon" in British Building Research Establishment and the "Thermoheliodon" in the School of Architecture, Princeton University. The main goal of these "artificial sky simulators" was to imitate the sun as the light source and to observe its effects. These examples, invented before the computer age, suffered from two handicaps. Olgyay describes the first disadvantage as the size of the light source and the optical apparatus, where the aim was to have parallel light rays similar to the sun. The second disadvantage was the excessive size of the simulators and their construction cost [9].

Following these old examples, some institutions like the Pacific Energy Centre in San Francisco have designed and built physical simulators such as the "Skydome". This device is "a machine that imitates the rotation and orbit of the Earth and it is a type of heliodon, which helps architects wanting to analyse passive solar heating options, site solar panels, or control solar heat gain" [10]. Scientists eliminated the problems of the old heliodons with new technological improvements but a physical model of this size is limited to near-by users. It is impractical for architects or building researchers from the rest of the world to use this physical model.

A related problem of locating light sources on a spherical surface is apparent in the field of the performing arts. In some live action compositing applications, an actor acts in front of a blue or green screen while graphics are projected on the screen, using computer software. Generally, the key problem is a mismatch between the actual lights on the actor and the virtual lights in the computer generated graphics. Debevec and colleagues [11] worked on a geodesic dome to prevent this ongoing conflict and designed a prototype. This model is useful for preventing a mismatch between the actual and the virtual; hence it improves the quality of a composited image. Lighting the face or body of an actor is similar to lighting a 3D art object. However, though they both use the same principles, in Debevec's dome the recording camera with a fixed position differs from the object in an exhibition case, where visitors can move around and experience the object freely.

Spherical lighting prototypes have been developed in museums as well as being used in architecture and the performing arts. In Britain, the Tate and the National Gallery worked on a prototype of an Imaging Dome. It enables researchers to do Polynomial Texture Mapping, which is "a process of capturing a special set of digital images of a painting, lit from different but measured angles" [12]. This prototype can be used effectively for creating a map of a two-dimensional painting surface. Although it is designed to archive a set of data about an artwork, it can be modified to improve exhibition conditions for visitors and it can help curators or lighting designers who are lighting the artwork.

\section{The proposed system: a lighting coordinate database}

Art objects in museums have identification cards which contain detailed information such as their names, inventory numbers, country of origins, materials, dates, artists or makers, descriptions, and dimensions. Every object listed in the inventory of a museum or an art gallery collection must have such a card. When an object moves from one museum to another, its identification card also goes with it. The proposed LCD is designed to be an essential addition to this object identification card; the information on light sources should be written on this identification card along with the other important data. A typical LCD is composed of three main parts. The first part concerns the "Lighting Parameters". In this part, the coordinates of light sources can be listed according to the degrees of azimuths and altitudes if the SLPS technique is used. The $x, y, z$ coordinates can be given if a computer system is used as the 
Table 1

A typical lighting coordinates database

Lighting coordinates database

Object information

Name of the art object

Identification number

Origin/country of the object

Date/era/period of its creation

Material

Dimensions in $\mathrm{cm}, \mathrm{H} / \mathrm{W} / \mathrm{D}$

Description

\section{Lighting parameters}

Light type

1. Key light

2. 1st fill light

3. 2nd fill light

4. 3rd fill light

5. Back light

This reference zero point location The software

Reflectance of near-by surfaces

Reflectance

Material

Colour

Physical surface property
Artist/designer of the object

\author{
Replica of David's head portion \\ 18 Ha SCAF \\ Unknown \\ Italy \\ 1990s \\ Marble \\ 28.6/16.4/15.8 \\ It is used for academic study
}

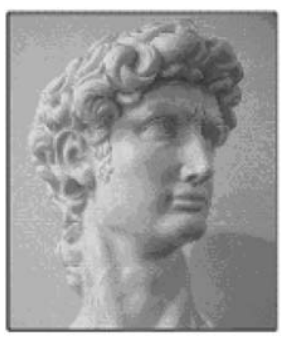

Lighting coordinates

\begin{tabular}{lllllll}
\hline$x$-Axis & $y$-Axis & $z$-Axis & & SD angle & CCT $(\mathrm{K})$ & CRI \\
\hline-1.96 & 1.70 & 1.92 & & 15 & 2500 & 95 \\
-2.05 & 0.48 & -0.83 & 15 & 2500 & 95 \\
-1.79 & -0.79 & -0.79 & & 15 & 2500 & 95 \\
0.39 & 1.52 & 0.38 & & 10 & 2500 & 95 \\
1.13 & -0.29 & 0.37 & 30 & 2500 & 95
\end{tabular}

Tip of the nose of David 3D Studio Max $\quad$ Version $\quad 5.0$

\begin{tabular}{|c|c|c|c|c|c|c|}
\hline Floor & Wall & Ceiling & $\mathrm{Nea}$ & bjects & & $L\left(\mathrm{~cd} / \mathrm{m}^{2}\right)$ \\
\hline NA & NA & NA & NA & NA & NA & NA \\
\hline NA & NA & NA & NA & NA & NA & NA \\
\hline NA & NA & NA & NA & NA & NA & NA \\
\hline
\end{tabular}

Legal information

Date of creating the database (day/month/year)

29.07.2003

This database was created under supervision of the following institute members
Name
R. Gilbert Smith
Affiliation
Sculptor
Signature

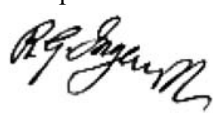
1. The light source is
Manufacturer

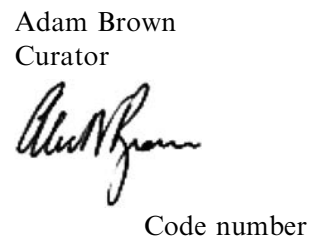
Adam Brown
Devid Downey
Lighting designer

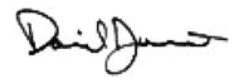

method of finding the coordinates. In addition to the coordinates of the light sources, the properties of the light emitted by the light sources and its effects on the surface of the object should be included in the database. These are the spectral distribution angle (SD angle), correlated colour temperatures (CCT), and colour rendering indexes (CRI) (Table 1).

"Reflectance" is the second part of a typical LCD. This part is specially designed to guide lighting designers or curators about the immediate surroundings of the art object. There are three parameters relating to reflectance of the nearby surfaces: material, colour and surface characteristics, whether specular or diffused. The luminance values $(L)$ in this section show the amount of light reflected from the art object's surface. This parameter helps lighting designers to choose the intensity of light sources.
The final part is "Legal Information". This section of the LCD includes the essential data about the date of creating the database and the name, affiliation and signatures of the institute members who supervised the creation of the database.

When an object and its identification card with the LCD arrives at a museum, the curators or lighting designers can use the coordinates of the light sources to locate their own lighting equipment correctly; it will be clear what types of light sources need to be used to illuminate the object because the LCD gives information about the desired appearance of the object. The LCD should result from a communication between the artist and the lighting designer. If the artists are living, they can help the lighting designers achieve the right effect. In other cases, where the artists are deceased or unknown, a committee of art 
historians and art critics may help to establish the database.

\section{The applications of the LCD}

A case study was conducted to test the applicability of the LCD. The major criterion for this case study was that the same object be evaluated by two methods, namely the computer software method and the SLPS hardware method. Using SLPS, it is possible to illuminate any physical object directly. An SLPS hardware prototype was designed in appropriate scale with the object used in the case study. On the other hand, to use the computer software, the object has to be translated into a data set by laser scanning to be defined in the virtual space. This expensive process needs special equipment, unless a pre-scanned art object is available. Data for a scanned art object, in this case the head of Michelangelo's David, was obtained from research conducted at Stanford University (Fig. 1).

During the establishment of an LCD, a lighting scheme has to be designed. The resulting effect has to reveal the emotion and the theme Michelangelo is believed to have tried to convey. In the case study, there were two kinds of data which guided the authors throughout the planning stage of the lighting scheme. The first kind drew on the historical and biographical information about Michelangelo's creation of David. The second kind of data comes from the orientation of the statue in the solar path.

First, to understand the emotional message of David, one should concentrate on its meaning. With its ill-proportioned hands and head, David is a naturalistic representation of adolescence [13]. The head of David is the most impressive part of the statue: "The thick, strained neck, furrowed brow and leonine hair all seem to indicate apprehensive defiance," says Hibbard [14]. The expression on his face shows wonder, and the fear of an anxious and hopeful young shepherd boy going to fight with Goliath (Fig. 2).

According to Wallace [15], the mop of hair, the furrowed brow, the deeply set eyes, the long straight nose, and

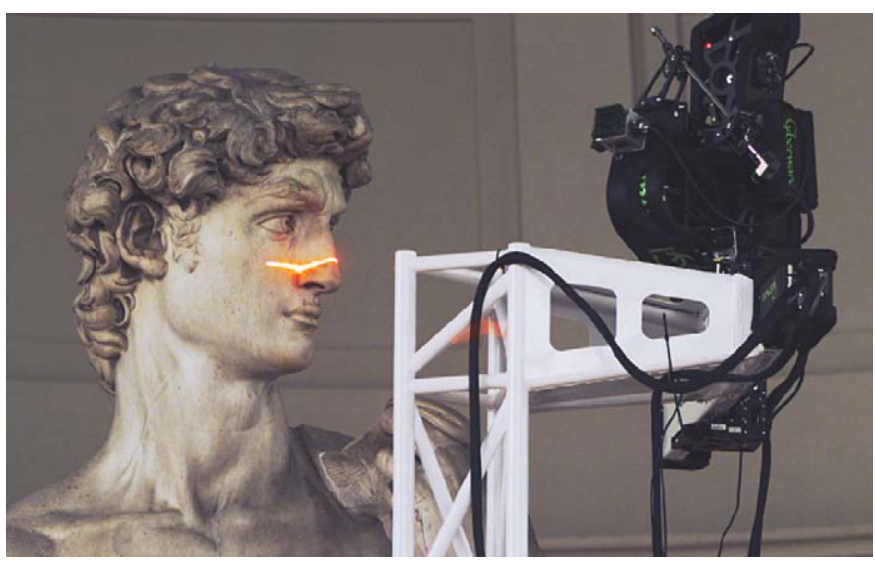

Fig. 1. Technical equipment, designed for scanning David. The laserscanning device is sending laser rays to its head. The picture shows the scaffold, built specially for the scanning process.

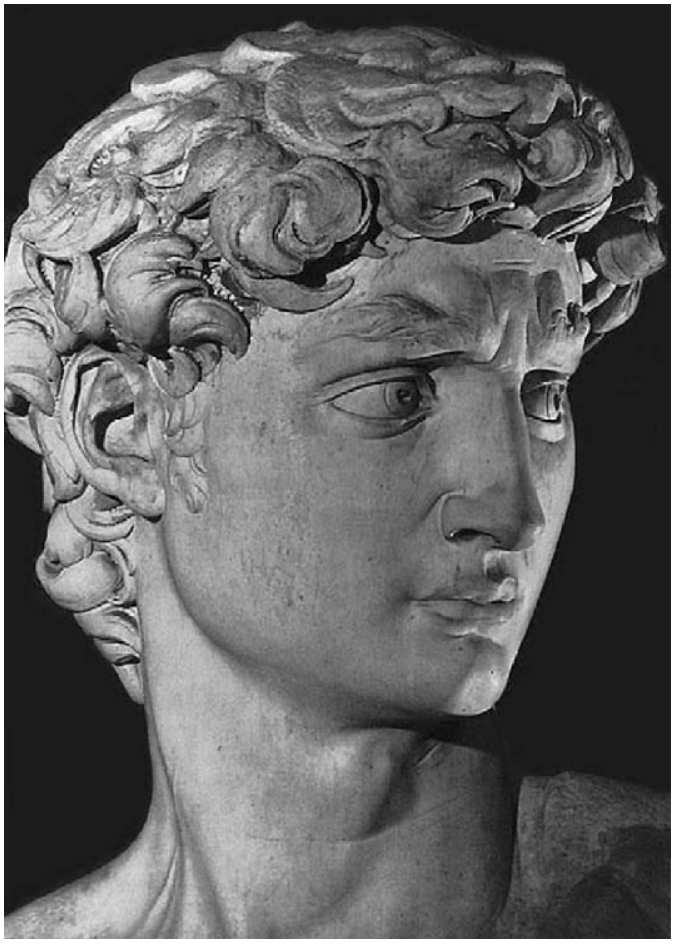

Fig. 2. Head portion of David

prominent lips are all features that lend intensity to the face. Using these observations, the impressions that Michelangelo would want to create on David's face by using artificial light sources can be predicted. With software and SLPS methods, an attempt can be made to reveal these features.

The second issue relates to the orientation of David. Archives reveal that a committee of outstanding artists of the Renaissance, including Leonardo Da Vinci and Sandro Botticelli, decided on the location of the statue in 1504, just after Michelangelo finished carving [16]. The statue had originally been commissioned by the Committee of Works of Florence Cathedral, the Duomo, and was located in front of the main façade of the Palazzo Vecchio. To protect it from outdoor conditions and vandalism, it is now in the Gallerie dell' Accademia in Florence. Although it is currently located inside, David was created to be exhibited in the open air, in front of a building. It was supposed to be standing under the bright sunny sky of Florence, and of course Michelangelo was aware of the visual effect of sunlight. In the replica of David, created to take the place of the original one as the original sculpture, the body is facing northwest but the head is turned towards the west.

Throughout the year, ignoring the changing effect of clouds, the sun shines for approximately $8 \mathrm{~h}$ a day. The changing direction of the solar rays and reflected components from the environment result in thousands of different lighting effects on the statue. Simulating those lighting conditions in a closed museum environment is very difficult, if not impossible. Simulating one specific date and time of the year would produce only one specific effect on David. In this paper, the aim is not to demonstrate how 


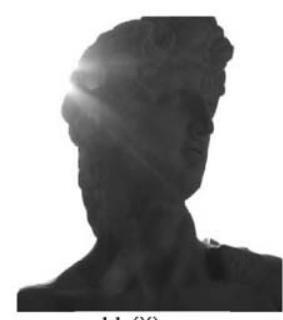

$11: 00 \mathrm{am}$

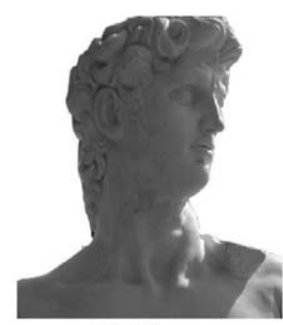

02:00 pm

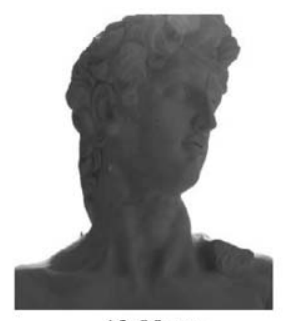

$12: 00 \mathrm{am}$

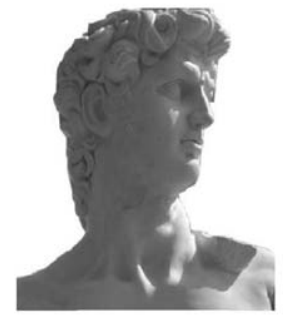

03:00 pm

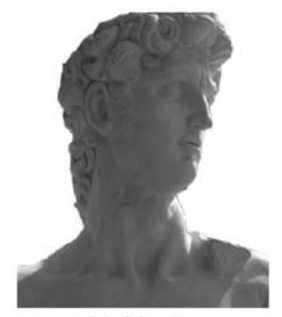

01:00 pm

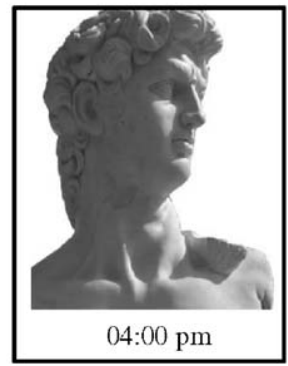

Fig. 3. Photographs of David under sunlight.

David would look like throughout the year as if it were standing in the open air, but to find a date and time of year when the statue can best be seen. Using a sundial and a scaled replica of David's head, the authors made hundreds of simulations. The appearance of the statue on the 21 st of March and the 21st of September between the hours of 11 a.m. and 4 p.m. were found to be effective (Fig. 3). By the authors, among these appearances, 4 p.m. is found as the most impressive.

Now, the aim was to simulate the effect on David of 4 p.m. light because for most of the year, the shadows and expressions of the face are perceived better then than at other times. When locating the artificial light sources, the location of the key light, the main light source, is important. Here, the key light has the same attitude and azimuth angles as the sun at 4 p.m. in Florence.

\subsection{Computer software procedure and results}

Bryan and Autif compared some common CAD software [17]. They compared two types of software: "2D CAD programs such as AutoCad and Archicad and 3D rendering programs like 3D Viz, 3D Max and FormZ'. They found that the strongest feature of 3D Max was its rendering capability. The authors likewise chose 3D Studio Max for this study [18]. In addition, this software uses enhanced lighting tools, such as Logarithmic Exposure Control, Pseudo Colour Exposure Control, and Global illumination. It uses Photometric Lights, which "are necessary to achieve accurate global illumination" and it also has some user friendly options such as Radiosity, "which is a physically accurate system, the goal of which is to render the same scene and obtain similar results, with no manual adjustments".

In order to locate the coordinates of any light source, it is essential to define a reference direction. In the same way,

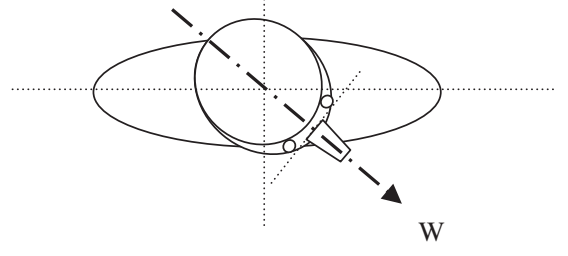

Fig. 4. Schematic top view drawing of David. Its head is looking left. The black arrow indicates the reference West.

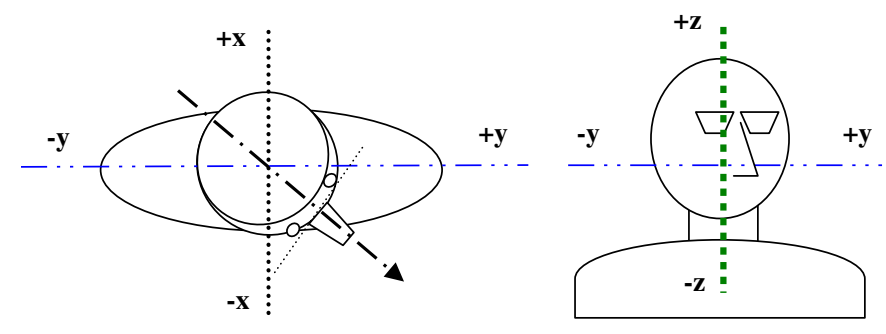

Fig. 5. Schematic top view and front view drawings of David.

a reference is needed to obtain the coordinates of virtual light sources. The original David stands facing west, so this direction is accepted as the reference direction (Fig. 4).

After the key light is located at the position of the sun at 4 p.m., on the 21 st of March and September, fill and back lights should be located to soften the shadows. To gain the effect we presume Michelangelo wanted, virtual light sources are located all around David's head by using the tools and options of the software. After locating all the light sources, the coordinates of each selected light source is stored. Because of the nature of the software, the final data set has three parameters; these are $x, y$ and $z$ (Fig. 5).

Taking the tip of the nose as point zero, where all three axes intersect, the coordinates of the light sources are determined. When writing the coordinates of the light sources, it is necessary to group them into three light types: key, fill, and back lights. Table 2 shows the coordinates of the light sources from this study.

\subsection{Lighting model procedure and results}

After preparing the setting and SLPS for the experiment, a replica of David's head is located on the object base. In this stage, a trial-and-error method is used because a lighting scheme on paper is generally different from the real-life application. The coordinate of a light source on the SLPS device has two parameters, altitude and azimuth. To find out the altitudes, vertical ribs have to be located on the appropriate holes of the base and headpieces of the SLPS. Altitudes are the vertical location of light sources on the ribs. In Fig. 6, the picture of the SLPS and altitude angles are shown.

LED lighting technology is the preferred light source on the SLPS device. Dikel and Yener [19] have previously listed the advantages of this technology. These light sources 
Table 2

Sample data obtained by the software method

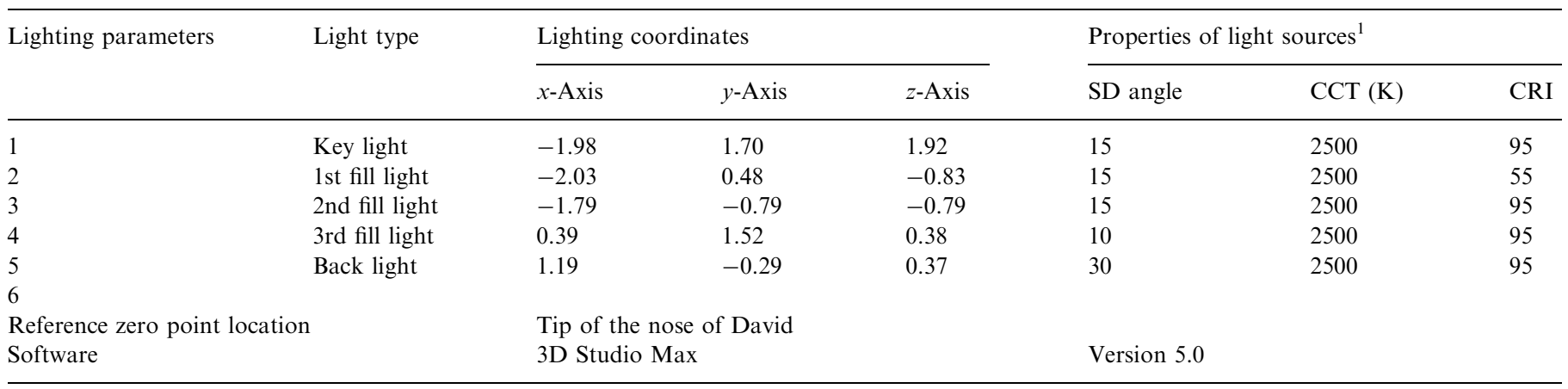
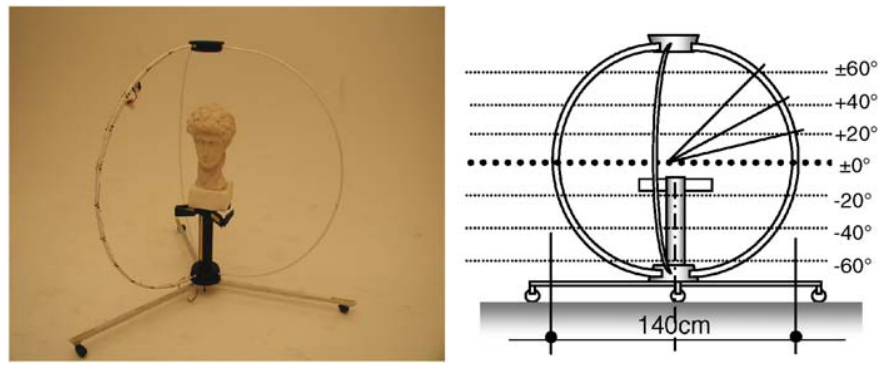

Fig. 6. Photograph and front view of SLPS and the altitude angles. The ribs of the SLPS prototype were made from aluminium tubes $8 \mathrm{~mm}$ in diameter. The head and base pieces are softwood, painted with black paint. The legs are $2 \mathrm{~cm} \times 2 \mathrm{~cm}$ aluminium profiles.

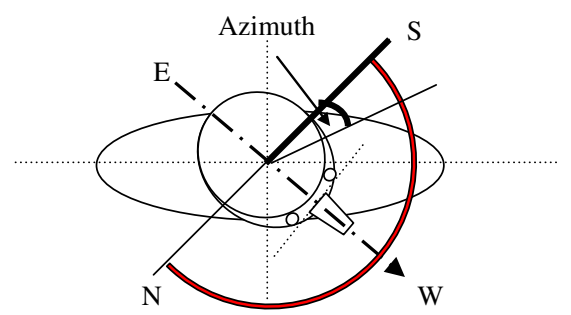

Fig. 7. Schematic top view drawing of David using the SLPS device. Its head is looking left. The black arrow indicates the reference degree zero.

can be turned off or dimmed by built-in dimmers. The scale and dimensions of the SLPS are specifically calculated for the replica of David's head. It is easily possible to create any desired lighting effect on its surface; however, using this hardware requires a skilled lighting technician to adjust the LEDs and make the electrical connections.

The Coordinates of the light sources can be found by locating the LEDs, beginning with the key light and moving to other lights. The reference west direction, as illustrated on Fig. 7, is a perpendicular line from David's head. By knowing where west is, any light source around the object has an azimuth angle in relation to south.

The final coordinates are shown in Table 3. The coordinates have two variables: altitude and azimuth. The azimuth angles have values related to the south in Fig. 7, beginning from 0 and progressing to $360^{\circ}$ in a clockwise direction; altitudes have positive and negative values as seen in Fig. 6. Using these coordinates, any lighting designer or curator in the future can easily illuminate David's head in an identical manner.

\section{Discussion}

If the two methods are examined, the SLPS method has one key advantage: it is real. No state-of-the-art virtual models or methods can outperform such an advantage. The effect of light sources on an object is best perceived in a physical model where people can walk around and look at it with their own eyes, rather than on a computer screen or other two-dimensional media.

By using computer software, we attempt to simulate reality. The success of this virtual reality is debatable, although Greenberg [20] claims that:

"[...] if the progress in computer graphics and hardware technology continue as of today, near the end of 2025 , the display and computational capability to produce images that are both physically accurate and perceptually indistinguishable from real world scenes will be available. This means that at that time simulation technology will reach such a level of capability that there will be no difference between real and virtual worlds and verification tools might be needed to avoid confusion between them".

SLPS devices have another advantage that they require less updating to maintain good performance and good results. The tubular aluminium ribs may be manufactured in ultra lightweight and durable materials, or the LEDs may become more flexible and easy to use. The movement of ribs and the alignment of LEDs can be controlled by computerized systems without ever touching them.

On the other hand, using computer software, one can locate the light sources at almost any desired angle with high accuracy, whereas on the prototype SLPS device that the authors designed, the angles are fixed at $30^{\circ}$ intervals. However, it is possible to design an SLPS device with finer or continuous settings. 
Table 3

Sample data obtained by the SLPS method

\begin{tabular}{|c|c|c|c|c|c|c|}
\hline Lighting parameters & Light type & \multicolumn{2}{|c|}{ Lighting coordinates } & \multicolumn{3}{|c|}{ Properties of light sources ${ }^{1}$} \\
\hline 2 & 1st fill light & 115 & -40 & 15 & 2500 & 95 \\
\hline 3 & 2nd fill light & 145 & -50 & 15 & 2500 & 95 \\
\hline 4 & 3rd fill light & 235 & +15 & 10 & 2500 & 95 \\
\hline \multicolumn{2}{|c|}{ Reference zero point location } & \multicolumn{5}{|c|}{ Tip of the nose of David } \\
\hline \multicolumn{2}{|c|}{ Method } & \multicolumn{5}{|l|}{ SLPS } \\
\hline
\end{tabular}

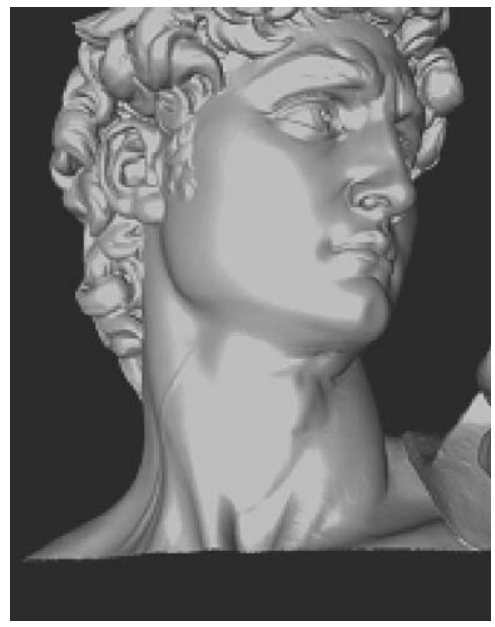

Fig. 8. David, illuminated by virtual light sources.

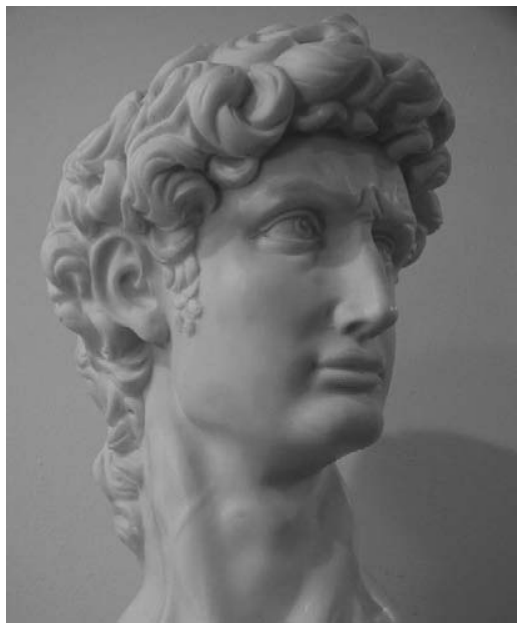

Fig. 9. David, illuminated by LED light sources.
In Fig. 8, David is illuminated by the virtual light sources located on the software. Due to the high detail level of laser scanning, every detail on his face can be seen and a minor change in the position of a light source can change the appearance of this sculpture. In Fig. 9, the photograph of David is taken after locating all the light sources on the SLPS. David's appearance is similar in both figures. David under the real lights of SLPS produces an effect of realism, which can hardly be obtained currently by using software.

Finally, when thinking about the two methods, it is also possible to think of computer software and the SLPS device working as a team. The lighting coordinates, found using the SLPS, can be used as the data for virtual light sources or vice versa.

\section{Conclusion}

If an art object, whether classical or modern, is to be exhibited for public viewing, so the object has to be illuminated. Currently, the methodology of illuminating art objects has usually ignored the artists' opinion on lighting. And, in every exhibition, different curators may illuminate the same object in different ways. The lighting coordinate database (LCD) proposed in this study reduces all these problems by helping curators or lighting designers to locate the light sources appropriately in an exhibition area. Two methods of obtaining data for the database have been explored, namely the software and hardware methods. Each method has its advantages and disadvantages and institutions can choose either method; the important thing is to understand the need for such a database and to use this database for current and future exhibitions.

Because the use of the SLPS device and computer software gives an opportunity to determine the coordinates of light sources, these coordinates could be the beginning of the lighting schemas of virtual museums. In the future, people can visit museums online; in this way, museums can open their collections to public access without the risk of vandalism, damage from light sources, or the environmental conditions of the exhibition halls. The 3D collections of museums could be virtually illuminated from the locations written on their LCDs. The honourable way to thank artists for their creations is to exhibit their artworks to current and future generations in the way they intended. Creating and using the LCD is one of the methods of doing this.

\section{Acknowledgements}

The authors would like to thank Associate Professor Marc Levoy, director of the "Digital Michelangelo Project" 
in the Computer Science Department at Stanford University, for his kind permission (April 12, 2003) to use the data set. The authors are also thankful to Dr. Mehmedalp Tural for his support during the preparation of the SLPS prototype sequences and taking the photographs.

\section{References}

[1] Illuminating Engineering Society of North America. Lighting handbook: reference and application CD-ROM. New York: Illuminating Engineering Society of North America; 2002 [Chapter 14].

[2] Illuminating Engineering Society. Lighting handbook: application volume. New York: Illuminating Engineering Society of North America; 1987 (p. 1).

[3] Veitch JA. Psychological processes influencing lighting quality. Journal of the Illuminating Engineering Society 2001;30:126.

[4] Illuminating Engineering Society of North America. Lighting handbook: reference and application CD-ROM. New York: Illuminating Engineering Society of North America; 2002 [Chapter 10].

[5] Illuminating Engineering Society of North America. Lighting handbook: reference and application CD-ROM. New York: Illuminating Engineering Society of North America; 2002 [Chapter 7].

[6] Illuminating Engineering Society of North America. Lighting handbook: reference and application CD-ROM. New York: Illuminating Engineering Society of North America; 2002 [Chapter 7].

[7] Illuminating Engineering Society. Museum and art gallery lighting: a recommended practice. New York: Illuminating Engineering Society of North America; 1996 (p. 3).

[8] Mueller-Mach R, Mueller GO, Krames MR, Trottier T. High-power phosphor converted light emitting diodes based on III-nitrides. IEEE Journal on Selected Topics in Quantum Electronics 2002;8:339-45.

[9] Olgyay V, Olgyay A. Solar control and shading devices. New Jersey: Princeton University Press; 1957 (p. 27).
[10] The PEC Heliodon. http://www.pge.com/003_save_energy/003c_edu_ train/pec/toolbox/arch/heliodon/heliodon.shtml. Access date: 08 February 2005.

[11] Debevec P, Wenger A, Tchou C, Gardner A, Waese J, Hawkins T. A lighting reproduction approach to live-action compositing. ACM Transactions on Graphics 2002;21(3):547-56.

[12] Frank A. Variable Light. http://www.tate.org.uk/collections/ptm/ technical.htm. Access date: 10 February 2005.

[13] Hughes A. Michelangelo. Boston: Phaidon; 1997 (p. 71).

[14] Hibbard H. Michelangelo: painter, sculptor, and architect. New Jersey: Chartwell; 1978 (p. 37).

[15] Wallace WE. Michelangelo: the complete sculpture, painting, and architecture. Hong Kong: Hugh Lauter Levin; 1998 (p. 61).

[16] Hughes A. Michelangelo. Boston: Phaidon; 1997 (p. 70).

[17] Bryan H, Autif SM. Shading Analysis: Analog vs. Digital Tools. www.caed.asu.edu/msenergy/Energy $\% 20 \& \% 20$ Climate $\% 20$ Papers/ shading_analysis.doc. Access date: 10 October, 2005.

[18] The User's Manual of 3D Studio Max. http://images.autodesk.com/ adsk/files/3dsMax8_techspec_rev.pdf. Access date: 10 October, 2005.

[19] Dikel E, Yener C. Thoughts on the usage of LED technology in museum lighting. In: Proceeding of the Sixth Istanbul Museum Seminar, Istanbul; 2002.

[20] Greenberg DP. In: Beatty JC, Kellog SB, editors. Computer graphics in architecture. Silverspring: IEEE Computer Society; 1982. p. 533-41.

Erhan Dikel is a Ph.D. student at Bilkent University, Turkey. In 2000, he received a Bachelor's degree, and in 2003 he received a Master in Fine Arts degree from the Interior Architecture and Environmental Design Department from the same university. His master thesis was entitled "Creating a Coordinate Database for the Lighting of Three Dimensional Art Objects", and he worked with Associate Professor Dr. Cengiz Yener on new technologies of museum lighting like light emitting diodes. He has attended several Museum Seminars. 